\title{
Association between self-efficacy and sociodemographic and clinical variables in patients with Diabetes Mellitus
}

\author{
Associação entre autoeficácia e variáveis sociodemográficas e \\ clínicas em pacientes com Diabetes Mellitus
}

Renata Aparecida do Nascimento', Rafaela Batista dos Santos Pedrosa ${ }^{2}$, Danilo Donizetti Trevisan ${ }^{3}$, Maria Helena de Melo Lima ${ }^{4}$, Thaís Moreira São-João ${ }^{4}$, Roberta Cunha Matheus Rodrigues ${ }^{4}$

\begin{abstract}
Model of study: A cross-sectional study was conducted. Objective: to evaluate the association between self-efficacy and socio-demographic and clinical variables in patients with type 2 diabetes mellitus (T2DM). Method: The sample was composed by 111 patients with T2DM in use of insulin, in primary health care units and outpatient setting in the southeast region of São Paulo state, Brazil. Sociodemographic data were gathered using validated questionnaire and clinical data were obtained from medical and health records. Self-efficacy was assessed by the Brazilian version of Insulin Management Diabetes Self-Efficacy Scale (IMDSES). The data were submitted to descrip-tive and comparative analyses using Mann-Whitney and Kruskal-Wallis to verify association be-tween socio- demographic/clinical variables and self-efficacy. Results: Self-efficacy was associ-ated with schooling level and presence of comorbidities, such as coronary artery disease, dyslipidemia, obesity, peripheral arterial disease and peripheral neuropathy. Conclusion: The findings provide support to the design some specifics interventions aimed at improving the self-efficacy of patients with T2DM on insulin use.
\end{abstract}

Keywords: Diabetes Mellitus. Self Efficacy. Cross-Sectional Studies. Nursing.

\section{RESUMO}

Modelo do estudo: Foi conduzido um estudo transversal. Objetivo: verificar a associação entre autoeficácia e variáveis sociodemográficas e clínicas em pacientes com diabetes mellitus. Métodos: A amostra foi composta por 111 pacientes com diabetes mellitus tipo 2 em uso de insulina em unidade básica de saúde e em ambulatório de hospital universitário da região sudeste do Estado de São Paulo, Brasil. Os dados sociodemográficos foram coletados usando questionário

1. Registered Nurse (RN), Ph.D student. Universidade de Campinas, Faculdade de Enfermagem. Campinas, SP, Brasil.

2. RN, Ph.D. Universidade de Campinas, Faculdade de Enfermagem. Campinas, SP, Brasil.

3. RN, PhD, Professor. Universidade Federal de São João Del-Rei, Campus de Divinópolis, MG, Brasil.

4. RN, PhD, Professor; Universidade de Campinas, Faculdade de Enfermagem. Campinas, SP, Brasil.

Disclosure of potential conflicts of interest: The authors have no conflicts of interest to disclose.
Corresponding

Danilo Donizetti Trevisan Universidade Federal de São João Del-Rei, Av. Sebastião Gonçalves Coelho, 400. Chanadour. 35501-296 - Divinópolis - MG, Brazil

Recebido em 03/10/2017 Aprovado em 26/06/2018 
validado e os dados clínicos foram obtidos dos prontuários do hospital e da unidade básica de saúde. A medida da autoeficácia foi obtida por meio da aplicação da Insulin Management Diabetes Self-Efficacy Scale - IMDSES. Para verificar a associação entre as variáveis sociodemográficas / clínicas e a autoeficácia foram utilizados os testes de Mann-Whitney e Kruskal-Wallis. Resulta-dos: A autoeficácia foi associada à escolaridade, presença de comorbidades e complicações do DM, como doença arterial coronária, obesidade, doença arterial periférica e neuropatia periférica. Conclusão: Os achados subsidiam o delineamento de intervenções para otimizar a autoeficácia em pacientes com diabetes mellitus em uso de insulina.

Palavras-chave: Diabetes Mellitus. Autoeficácia. Estudos Transversais. Enfermagem.

\section{INTRODUCTION}

Approximately 347 million people are affected by diabetes mellitus (DM) worldwide. $^{1}$ In Brazil, in 2013, it was estimated that just under 12 million in the age group of 20-79 years old were affected by DM and costs for their treatment and monitoring may reach 3.9 billion dollars a year to the government. 2,3

The development of strategies to provide behavior change and adoption of healthy prac- tices (i.e., healthy food behavior, physical activity, selfmonitoring of blood glucose, meticulous foot care and adherence to medication) is essential to manage and control the disease. ${ }^{4}$

Sociodemographic characteristics have been observed to affect the severity of DM. Edu-cational level, for example, is a key determinant of DM mortality in both sexes, and is more rel-evant in women, while marital status also plays an outstanding role in men. ${ }^{5}$ Increased risk of cardiovascular diseases, cancer and mortality are well stablished among patients with Type-2 Diabetes Mellitus (T2DM). ${ }^{6}$

The literature has reported that psychosocial factors such as self-efficacy also affect - positively or negatively - the medication adherence of the patients with T2DM. Therefore, factors as perceptions related to their illness including symptoms, consequences and curability; perceptions of medications including safety concerns, convenience and their necessity; religious healing practices and beliefs; perceptions about and experiences with their healthcare providers and the healthcare system including the availability of medications and diabetes education - were perceived as barriers to adhere to drug treatment.
Nevertheless, perceived self-efficacy and social support were assessed as facilitators in engag-ing in T2DM drug treatment. 7

The self-efficacy construct refers to one's beliefs or confidence in their ability to successfully perform a task to achieve the desired outcome. ${ }^{8}$ This construct assumes that the initiation, maintenance or withdrawal of a behavior is also influenced by the person's beliefs in his/hers ability to overcome environmental barriers to implementation. ${ }^{9}$ Therefore, there are reports suggesting that strengthening self-efficacy relates to healthy behaviors in patients with type (T2DM). 10,11 Previous studies ${ }^{10,12}$ have shown that self-efficacy influenced self-care behavior in Chinese and Americans patients with T2DM.

However, the association between self-efficacy and sociodemographic and clinical variables in patients with T2DM in the Brazilian context has been little investigated. The elucidation of this association should provide support for the development of specific interventions aimed at improving self-efficacy of patients with T2DM.

Considering the importance of self-efficacy in the management of T2DM, this study was aimed at evaluating the association between self-effi- cacy and sociodemographic and clinical variables in T2DM outpatients.

\section{METHODS}

\section{Design and Setting}

A cross-sectional study was carried out in a primary health unit and in an outpatient setting at a university hospital, in the southeast region of São Paulo state, Brazil. 


\section{Participants and data collection}

This study enrolled 111 patients with T2DM in regular follow up at the above-mentioned set- tings, aged over 18 years old. We included T2DM oupatients on insulin use for at least one year and with oral communication skills - those capa-ble of comprehending and speaking Brazilian Portuguese in order to be interviewed. Those pa- tients with chronic complications of T2DM in the advanced stage, as chronic renal failure under- going hemodialysis, blindness, heart failure class III and IV and those patients with physical se- quelae of stroke, were excluded.

The data were collected by two of the researchers (RAN and DDT) by interview, in a private room, during the interval between medical and/or nursing appointments in referenced fields of research.

The patient was initially approached to exposure the aim of the study and obtaining the agreement to engage in study by signing the Informed Consent Form. Then, the structured interview technique was used to gather sociodemographic and clinical data, as well as measure selfefficacy by application of the Brazilian version of IMDSES scale. ${ }^{13}$ After, the complementary clinical data (length of T2DM diagnosis, comorbidities, fasting glucose and glycated hemoglobin - HbA1c) was obtained.

\section{Data collection}

\section{Sociodemographic and clinical variables}

The sociodemographic and clinical data were obtained by previously validated instru- ment, ${ }^{14}$ consisting of the items:

- Sociodemographic data: gender, age, schooling (completed years of education), family arrangement, employment and personal and family monthly income in minimum wages;

- Clinical data: lenght of diagnosis and treatment of T2DM, length of insulin use, number of classes of medications in use, habits (smoking) and comorbidities - hypertension, coronary artery disease (myocardial infarction or angina), stroke, dyslipidemia, obesity (evaluated by the body mass index - BMI $330.0 \mathrm{~kg} / \mathrm{m}^{2}$ ), metabolic syndrome and peripheral arterial disease. Data on symptoms perceived over the prior month to the interview (such as involuntary weight loss, fatigue or blurred vision); signals as hyper/hypoglycemia and complications of T2DM (retinopathy and neuropathy) were en-rolled. Anthropometric data were obtained (weight, abdominal circumference height, waist circumference) and laboratorial exams results

(fasting glucose and $\mathrm{HbA}_{1} \mathrm{C}$ ) - were gathered if they were collected up to three months before the interview.

\section{Insulin Management Diabetes Self- \\ Efficacy Scale - IMDSES}

The IMDSES was created in American culture by Hurley and Harvey ${ }^{15}$ to measure self-efficacy related to self-care of DM between patients on insulin therapy. ${ }^{15,16}$ The scale is composed of 28 items, which measure seven types of behavior: general, diet, exercise, foot care, blood glucose monitoring, insulin administration; and detection, prevention treatment of hypoglycemia/hyperglycemia. The items are distributed over three subscales: General, Diet and Insulin.

As for the scoring, the answers are rated on a Likert-type scale of six points ( $1=$ strongly agree, $2=$ moderately agree, $3=$ slightly agree, $4=$ slightly disagree, $5=$ moderately disagree, $6=$ strongly disagree). In the original scale, the items $(4,8,9$, $13,16,22,25$ and 26) were set in nega-tive mode. The psyhometric properties of the origi-nal version presented satisfactory evidences of reliability by Cronbach's alpha coefficient $(\alpha)$ - total score $(\alpha=$ $0.82)$, General $(\alpha=0.67)$, Diet $(\alpha=0.78)$ and Insulin $(\alpha=0.77)$.

The Brazilian version of IMDSES, proposed by Gastal et al., ${ }^{13}$ is composed by 20 items, distributed in the same domains, since the items which presented factor loadings $<0.30$ in factor analysis were excluded $(12,13,14,15,16,17,18$, and 25). In this version, the sequence of items was modified and some of them $(4,8,9,22,25$ and 26$)$ were set in affimative mode. One item (item 20) had its text slightly modified. The an- swers are rated on a Likert-type scale of four points ( $1=$ strongly agree, $2=$ agree, $3=$ disagree and $4=$ strongly disagree) and the option " $d$ 
not apply" was included. The scoring was obtained by the sum of the scores, which ranged from 28 to112; in the item 13 (drafted in the negative mode) reverse scoring was used for calculating the total score. For the interpreting the Brazilian version of IMDSES, the higher the score, the lower the self-efficacy.

Nevertheless, in our study, the 28-item Brazilian version was chosen, in order to allow comparison between current results and those of the original scale. Therefore, items are distributed over subscales as following: from 1 to 11 , in the Diet subscale; from 12 to 18 , in the Insulin subscale; and from 19 to 28, in the General subscale. The total score comprises the sum of the three subscales. The complete Brazilian version of IMDSES showed evidence of reliability by Cronbach's al-pha coefficient for Insulin $(\alpha=0.82)$ and Diet $(\alpha=0.64)$ subscales. The General subscale pre-sented $\alpha$ of 0.50 .

\section{Data analyses}

The Statistical Package for the Social Sciences (SPSS) for Windows, version 21.0 was used for the analysis. Frequency tables, position measurements (mean, median and range) and dispersion (standard deviation) were used for the descriptive analysis of sociodemographic/clinical variables and scores of the Brazilian version of IMDSES. Reliability regarding internal consistency was estimated by Cronbach's alpha ( $\alpha$ ) coefficient and it was established $\alpha>.70$ as evidence of in- ternal consistency. Mann-Whitney and Kruskal- Wallis test were used to compare self-efficacy across sociodemographic (gender, age, education, place of residence, family structure and family in- come) and clinical variables (co-morbidities symp- toms, DM complications, blood glucose and HbA1c). A significance level of $5 \%$ was adopted.

\section{Ethical considerations}

The local ethics committee approved the study (Protocol: no 1180/2011). The authors (RAN and DDT) explained the aim of the study and procedure of data collection to potential participants. The enrolled patients signed the Informed Consent.

\section{RESULTS}

We found a predominance of women $(64.8 \%)$, whose mean age was of 58.2 (9.0) years old, with an average schooling of 6.1 (4.5) years of study, who lived with partners and/or other family members (90.9\%). Regarding clinical pro- file, the average length of treatment of T2DM was

14.5 (9.2) years, with a mean insulin use length of 7.5 (6.7) years. Concerning the comorbidities, hypertension (54.1\%) and obesity (64.9\%) stood out. The blurred vision was the most often reported symptom (45.9\%), on the month prior to the interview. The findings showed average $\mathrm{HbA} 1 \mathrm{C}$ level above recommended (see Table 1).

The results showed higher IMDSES scores for the General subscale and for the total score, which indicate lower self-efficacy relating to self- care of diabetes (Table 2).

The patients with lower schooling levels, which reported less than or equal to three completed years of study, had lower self-efficacy in the General subscale, compared to those who reported greater than or equal to three completed years of study ( $p=0.05$; Mann-Whitney test) (Ta- ble 3 ).

The data showed smaller self-efficacy scores of IMDSES for the Diet subscale among patients with coronary artery disease $(p$-value $=0.04)$ and greater self-efficacy for those who presented weight reduction ( $p$-value $=0.02$ ). Regarding the Insulin subscale, greater self-efficacy was observed among those who had dyslipidemia ( $p$ - value $=0.006$ ). As for the General subscale, smaller self-efficacy was observed among those who had: CAD ( $p$ value $=0.02)$, dyslipidemia $(p$ - value $=0.01)$, obesity $(p$-value $=0.04)$, peripheral artery disease ( $p$ value $=0.03$ ) and peripheral neu- ropathy ( $p-$ value $=0.002$ ) (see Table 4).

\section{DISCUSSION}

This study was aimed at evaluating the association between self-efficacy and sociodemographic and clinical variables in T2DM outpatients. The main findings showed that self-efficacy measured by the Brazilian version of the IMDSES was associated with socio-demographic variables (schooling) and clinical variables, especially with 
Table 1.

Sociodemographic and clinical profile of outpatients with type 2 diabetes mellitus, in use of insulin $(n=111)$.

\begin{tabular}{|c|c|c|c|c|}
\hline Socio-demographic and clinical variables & $\%(n)$ & Mean (SD) ${ }^{*}$ & Median & Range \\
\hline \multicolumn{5}{|l|}{ Gender } \\
\hline Female & $64.8(72)$ & & & \\
\hline Age (in years) & & $58.2(9.0)$ & 58.0 & $34.0-81.0$ \\
\hline Schooling & & $6.1(4.5)$ & 5.0 & $0.0-25.0$ \\
\hline \multicolumn{5}{|l|}{ Living with: } \\
\hline Alone & $9.0(10)$ & & & \\
\hline Partner and/or family member & $90.9(101)$ & & & \\
\hline \multicolumn{5}{|l|}{ Smoking } \\
\hline Yes & 11.7 (13) & & & \\
\hline No & $88.3(98)$ & & & \\
\hline \multicolumn{5}{|l|}{ DM Treatment time } \\
\hline Onset of treatment & & $14.5(9.2)$ & 14.0 & $1.0-40.0$ \\
\hline Onset of using insulin & & $7.5(6.7)$ & 5.0 & $0.0-32.0$ \\
\hline
\end{tabular}

Symptoms (month before the interview)
Nephropathy
$27.0(30)$
Retinopathy
$42.3(47)$
Peripheral neuropathy

\section{Comorbidities}

Hypertension

Coronary artery disease

Stroke (without cognitive deficit)

Dyslipidemia

Obesity

Metabolic syndrome

Peripheral Arterial Disease

\section{Complications of DM}

Nephropathy

Retinopathy

Peripheral neuropathy
$27.0(30)$

42.3 (47)

$54.1(60)$

17.1 (19)

$9.0(10)$

$41.4(46)$

$64.9(72)$

$41.4(46)$

$9.9(11)$

$21.6(24)$

\section{Tests results}

Fasting glucose

$\mathrm{HbA}_{1 \mathrm{C}}$

Note: $: S D=$ Standard Deviation .
$172.3(104.1) \quad 140.0 \quad 53.0-800.0$

$9.4(2.1) \quad 9.2 \quad 5.9-14.9$


Table 2.

Descriptive analysis of the performance of the Brazilian version of Insulin Management Diabetes Self-Efficacy Scale IMDSES in outpatients with type 2 diabetes mellitus (T2DM) in use of insulin $(n=111)$.

\section{IMDSES subscales}

$\begin{array}{lllll}\text { Diet } & 11 & 2.4(0.3) & 2.4 & 1.5-3.4 \\ \text { Insulin } & 07 & 1.8(0.5) & 1.8 & 0.6-3.0 \\ \text { General } & 10 & 2.6(0.4) & 2.6 & 1.7-3.6 \\ \text { Total Score } & 28 & 6.8(0.7) & 6.8 & 4.6-8.9\end{array}$

Note: *SD = Standard Deviation

Table 3.

Comparison analysis between of Brazilian version of Insulin Management Diabetes Self-Efficacy Scale - IMDSES and socio-demographic variables in outpatients with type 2 diabetes mellitus (T2DM) $(n=111)$.

Self-efficacy - IMDSES

\begin{tabular}{lcccc} 
& \multicolumn{4}{c}{ Self-efficacy - IMDSES } \\
\cline { 2 - 5 } Sociodemographic variables & $\begin{array}{c}\text { Diet } \\
\text { Mean(SD) }\end{array}$ & $\begin{array}{c}\text { Insulin } \\
\text { Mean(SD) }\end{array}$ & $\begin{array}{c}\text { General } \\
\text { Mean(SD) }\end{array}$ & $\begin{array}{c}\text { Total sCore } \\
\text { Mean (SD }\end{array}$ \\
\hline $\begin{array}{l}\text { Gender } \\
\text { Female }\end{array}$ & $2.4(0.3)$ & $1.7(0.5)$ & $2.6(0.4)$ & $6.8(0.7)$ \\
Male & $2.4(0.4)$ & $1.8(0.5)$ & $2.6(0.4)$ & $6.8(0.7)$ \\
p-value* & 0.67 & 0.15 & 0.80 & 0.59
\end{tabular}

Age

$18 \delta$ years old $\delta 60$

$>60$ years old

p-value*

Education

$\delta 3$ years of study

$>3$ years of study

p-value*

\section{Living with}

Alone

Partner/family member

p-value*

\section{Family income}

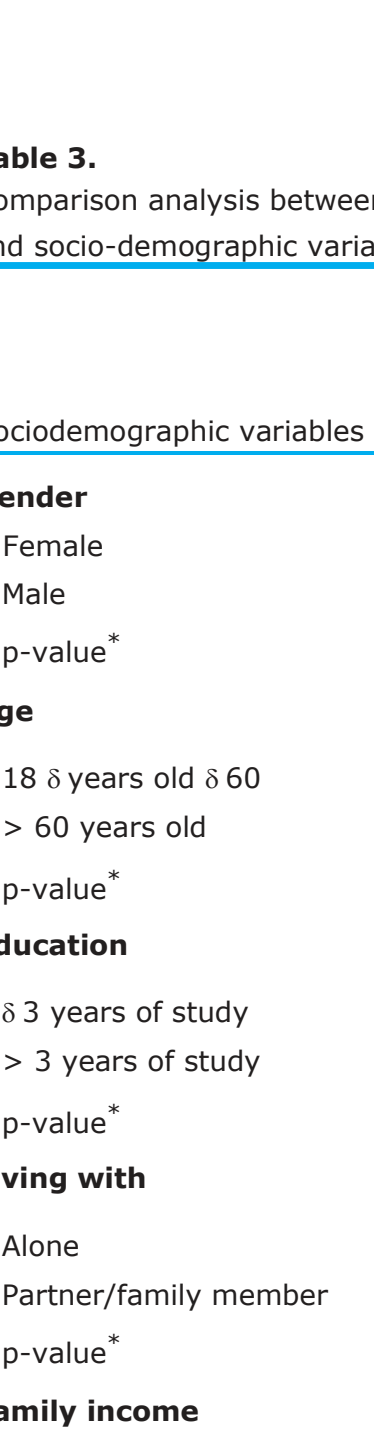

$\delta 1 \mathrm{MW}$

$2 \delta M W \delta 4$

$>4 \mathrm{MW}$

2.4(0.3)

1.7(0.4)

$1.9(0.5)$

0.39

0.08

2.4(0.3)

$1.9(0.6)$

2.4(0.4)

1.7(0.4)

0.77

0.05

2.5(0.3)

1.7(0.4)

$1.8(0.5)$

0.49

0.37

2.4(0.4)

$1.7(0.5)$

$2.8(0.4)$

$6.9(0.8)$

2.4(0.3)

$1.7(0.5)$

2.6(0.4)

$6.8(0.7)$

$2.4(0.3)$

$1.7(0.4)$

$2.7(0.4)$

$6.7(0.6)$

p-value ${ }^{\dagger}$

0.95

0.10

0.22

0.94

Note: ${ }^{a_{M a n n}-W h i t n e y ~ t e s t ; ~}{ }_{\dagger}$ Krukal-Wallis test; $M W=$ Minimum Wages. 
Table 4.

Comparison analysis between of Brazilian version of Insulin Management Diabetes Self-Efficacy Scale IMDSES and clinical variables in outpatients with type 2 diabetes mellitus (T2DM) $(n=111)$.

\begin{tabular}{|c|c|c|c|c|c|}
\hline \multirow[b]{2}{*}{ Clinical variables } & \multicolumn{5}{|c|}{ Self-efficacy - IMDSES } \\
\hline & & $\begin{array}{l}\text { et } \\
\text { (SD) }\end{array}$ & $\begin{array}{c}\text { Insulin } \\
\text { Mean(SD) }\end{array}$ & $\begin{array}{c}\text { General } \\
\text { Mean(SD) }\end{array}$ & $\begin{array}{l}\text { Total score } \\
\text { Mean (SD) }\end{array}$ \\
\hline \multicolumn{6}{|l|}{ Co-morbidities } \\
\hline \multirow[t]{3}{*}{ Hypertension } & Yes & $2.4(0.2)$ & $1.8(0.3)$ & $2.5(0.4)$ & $6.6(0.5)$ \\
\hline & No & $2.4(0.4)$ & $1.8(0.5)$ & $2.6(0.4)$ & $6.8(0.7)$ \\
\hline & p-value* & 1.0 & 0.91 & 0.06 & 0.31 \\
\hline \multirow[t]{3}{*}{ Coronary artery disease } & Yes & $2.4(0.3)$ & $1.8(0.4)$ & $2.6(0.4)$ & $6.7(0.6)$ \\
\hline & No & $2.5(0.4)$ & $1.7(0.6)$ & $2.7(0.4)$ & $7.0(0.8)$ \\
\hline & p-value* & 0.04 & 0.64 & 0.02 & 0.07 \\
\hline \multirow[t]{3}{*}{ Dyslipidemia } & Yes & $2.3(0.3)$ & $2.0(0.3)$ & $2.5(0.3)$ & $6.7(0.5)$ \\
\hline & No & $2.4(0.3)$ & $1.7(0.5)$ & $2.7(0.4)$ & $6.8(0.8)$ \\
\hline & p-value* & 0.08 & 0.006 & 0.01 & 0.67 \\
\hline \multirow[t]{3}{*}{ Stroke } & Yes & $2.4(0.3)$ & $1.8(0.5)$ & $2.6(0.4)$ & $6.8(0.7)$ \\
\hline & No & $2.5(0.4)$ & $1.9(0.4)$ & $2.5(0.4)$ & $6.9(0.8)$ \\
\hline & p-value* & 0.27 & 0.55 & 0.31 & 0.41 \\
\hline \multirow[t]{3}{*}{ Obesity } & Yes & $2.3(0.3)$ & $1.9(0.4)$ & $2.5(0.4)$ & $6.7(0.6)$ \\
\hline & No & $2.4(0.3)$ & $1.7(0.5)$ & $2.6(0.4)$ & $6.8(0.7)$ \\
\hline & p-value* & 0.08 & 0.09 & 0.04 & 0.22 \\
\hline \multirow[t]{3}{*}{ Metabolic syndrome } & Yes & $2.3(0.3)$ & $1.9(0.4)$ & $2.6(0.3)$ & $6.8(0.7)$ \\
\hline & No & $2.4(0.4)$ & $1.7(0.5)$ & $2.6(0.4)$ & $6.8(0.7)$ \\
\hline & p-value* & 0.17 & 0.16 & 0.28 & 0.75 \\
\hline \multirow[t]{3}{*}{ Peripheral Arterial Disease } & Yes & $2.4(0.3)$ & $1.8(0.5)$ & $2.6(0.4)$ & $6.7(0.6)$ \\
\hline & No & $2.4(0.4)$ & $1.8(0.5)$ & $2.8(0.4)$ & $7.1(0.9)$ \\
\hline & p-value* & 0.39 & 0.75 & 0.03 & 0.08 \\
\hline \\
\hline \multirow{3}{*}{$\begin{array}{l}\text { Complications of DM } \\
\text { Nephropatthy }\end{array}$} & Yes & $2.4(0.3)$ & $1.8(0.5)$ & $2.6(0.4)$ & $6.8(0.7)$ \\
\hline & No & $2.4(0.4)$ & $1.8(0.5)$ & $2.6(0.4)$ & $6.8(0.8)$ \\
\hline & p-value* & 0.76 & 0.76 & 0.69 & 0.60 \\
\hline \multirow[t]{3}{*}{ Retinopathy } & Yes & $2.3(0.4)$ & $1.9(0.5)$ & $2.7(0.4)$ & $7.0(0.8)$ \\
\hline & No & $2.4(0.3)$ & $1.7(0.4)$ & $2.6(0.4)$ & $6.7(0.7)$ \\
\hline & p-value* & 0.43 & 0.09 & 0.24 & 0.49 \\
\hline \multirow[t]{3}{*}{ Peripheral neuropathy } & Yes & $2.4(0.3)$ & $1.8(0.3)$ & $2.5(0.3)$ & $6.7(0.6)$ \\
\hline & No & $2.4(0.4)$ & $1.8(0.5)$ & $2.7(0.4)$ & $6.9(0.8)$ \\
\hline & p-value* & 0.96 & 0.96 & 0.002 & 0.07 \\
\hline \multicolumn{6}{|l|}{ Symptoms } \\
\hline \multirow[t]{3}{*}{ Hyperglycemia / hypoglycemia } & Yes & $2.4(0.3)$ & $1.8(0.4)$ & $2.5(0.3)$ & $6.7(0.6)$ \\
\hline & No & $2.4(0.4)$ & $1.7(0.5)$ & $2.7(0.4)$ & $6.8(0.9)$ \\
\hline & p-value* & 0.53 & 0.36 & 0.06 & 0.48 \\
\hline \multirow[t]{3}{*}{ Blurred vision } & Yes & $2.4(0.4)$ & $1.7(0.5)$ & $2.6(0.4)$ & $6.7(0.7)$ \\
\hline & No & $2.4(0.3)$ & $1.8(0.5)$ & $2.6(0.4)$ & $6.7(0.7)$ \\
\hline & p-value* & 0.21 & 0.34 & 0.72 & 0.08 \\
\hline \multirow[t]{3}{*}{ Weight reduction } & Yes & $2.5(0.3)$ & $1.8(0.5)$ & $2.7(0.4)$ & $6.9(0.7)$ \\
\hline & No & $2.3(0.3)$ & $1.8(0.4)$ & $2.5(0.4)$ & $6.6(0.6)$ \\
\hline & p-value* & 0.02 & 0.67 & 0.09 & 0.09 \\
\hline \multicolumn{6}{|l|}{ Laboratorial results } \\
\hline \multirow[t]{4}{*}{$\mathrm{HbA}_{1 \mathrm{C}}$} & $<6,0$ & $2.4(0.4)$ & $1.7(0.5)$ & $2.6(0.4)$ & $6.7(0.7)$ \\
\hline & $6,0-8,6$ & $2.3(0.2)$ & $2.1(0.8)$ & $2.2(0.7)$ & $6.6(0.8)$ \\
\hline & $>8,6$ & $2.4(0.3)$ & $1.8(0.5)$ & $2.6(0.4)$ & $6.8(0.7)$ \\
\hline & p-value ${ }^{+}$ & 0.57 & 0.48 & 0.64 & 0.67 \\
\hline Fasting glucose & $<70$ & $2.5(0.4)$ & $1.7(0.7)$ & $2.4(0.7)$ & $6.6(0.9)$ \\
\hline & $70-100$ & $2.4(0.3)$ & $1.8(0.4)$ & $2.4(0.3)$ & $6.6(0.7)$ \\
\hline & $>100$ & $2.4(0.4)$ & $1.8(0.5)$ & $2.6(0.4)$ & $6.8(0.7)$ \\
\hline & p-value ${ }^{+}$ & 0.95 & 0.97 & 0.08 & 0.62 \\
\hline
\end{tabular}

Note: *Mann-Whitney test; †Kruskal-Wallis test. 
comorbidites (coronary artery disease, obesity, peripheral arterial disease) and peripheral neuropathy - one of the complications of T2DM.

The relationship between self-efficacy and the incorporation of health behavior has been explored in several studies. ${ }^{17,18}$ As regarding the T2DM, which is a chronic disease, whose treatment imposes a significant change in patient's lifestyle, the self-efficacy has been pointed as one of the variables present in strategies used to achieve the goal of changing behavior.

In our study, when analyzing the association between self-efficacy and sociodemographic and clinical variables, there was a statistically significant association between schooling level and the General subscale of the Brazilian version of IMDSES. Similar finding has been evidenced in previous studies, ${ }^{17,19}$ which was demonstrated that schooling level was a significant predictor of self-efficacy.

As regarding the comparison analysis between self-efficacy and clinical variables, we found statistically significant association between patients with a lower score of self-efficacy in the Insulin and General subscales of IMDSES and presence of comorbidities. A previous study, ${ }^{20}$ which enrolled 388 patients with T2DM, showed that people without comorbidities and T2DM complications were more confident to perform the activi-ties required for T2DM treatment. However, an-other study $^{21}$ conducted with ethnically diverse individuals, showed no association between selfefficacy and comorbidities, such as hypertension and dyslipidemia.

Our study also showed higher total scores, indicating greater impairment of total self-efficacy level among the subjects who had T2DM complications. Therefore, the current data suggest that the severity of the T2DM, considering the presence of comorbidities, complications of T2DM and irregu-lar metabolic control, was associated with minor selfefficacy to manage the disease. This result shows the pivotal role of nurses in recognizing the vulnerability of these patients in the management of T2DM and the critical need of outlining interven-tions aimed to improve patients's understanding about the treatment regimen and skills to use in-sulin, strengthening their self-efficacy in the man-agement and adherence to medication.
The findings of this study subsidize a bet-ter comprehension of the association between selfefficacy and sociodemographic and clinical variables. Further studies are recommended in order to investigate self-efficacy barriers and/or facilitators to adherence to medication and nonmedication treatment of patients with T2DM.

\section{CONCLUSION}

The findings of this study suggest that low schooling level and the presence of comorbidities and complications of T2DM were significantly associated with lower self-efficacy in patients with T2DM on insulin therapy. These data subsidizes the design of specific interventions aiming at in- crease self-efficacy for the treatment and, hence, the better management of the disease in T2DM outpatients.

\section{Conflict of interest}

The authors declare no conflict of interest. This study was funded by Foundation for Research Support of the State of São Paulo - FAPESP (Process No. 2011 / 19985-1).

\section{REFERENCES}

1. Danaei G, Finucane MM, Lu Y, Singh GM, Cowan MJ, Paciorek $\mathrm{C}$, et al. National, regional, and global trends in fasting plasma glucose and diabetes preva-lence since 1980: systematic analysis of health ex-amination surveys and epidemiological studies with 370 country-years and 2.7 million participants. Lan-cet. 2011;378:31-40.

2. Inzucchi $S E$, Bergenstal $R M$, Buse JB, Diamant $M$, Ferrannini E, Nauck M, et al. Management of hyperglycaemia in type 2 diabetes: a patient-centered ap- proach. Position statement of the American Diabe-tes Association (ADA) and the European Association for the Study of Diabetes (EASD). Diabetologia. 2012;55:1577- 96.

3. Inzucchi $S E$, Bergenstal $R M$, Buse JB, Diamant $M$, Ferrannini E, Nauck M, et al. Management of hyperglycemia in type 2 diabetes, 2015: a patient-centered approach: update to a position statement of the American Diabetes Association and the European Association for the Study of Diabetes. Diabetes Care. 2015;38:140-9.

4. Association AD. 1. Strategies for Improving Care. Diabetes Care. 2016;39 Suppl 1:S6-12.

5. Escolar-Pujolar A, Doña JAC, Julían IG, Rodríguez GJ, Sánchez VS, Sánchez EM, Diosdado MA. The effect of marital status on social and gender inequalities in diabetes mortality in Andalusia. Endocrino-logía, Dia- betes y Nutrición (English ed.) 2018; 65: 21-9. 
6. Wild SH, Walker J., Morling JR, McAllister DA, Colhoun HM, Farran B, et al. Cardiovascular disease, cancer, and mortality among people with type 2 diabetes and alcoholic or nonalcoholic fatty liver disease hos-pital admission. Diabetes Care. 2018; 41:341-7.

7. Habte BM, Kebede T, Fenta TG, Boon H. Barriers and facilitators to adherence to anti-diabetic medications: Ethiopian patients' perspectives. African Journal of Primary Health Care \& Family Medicine. 2017;9(1):1411. doi: 10.4102/phcfm.v9i1.1411.

8. Bandura A. Social foundations of thought and ac-tion: A social cognitive theory. New Jersey, NJ: Prentice Hall.; 1986. 39-453 p.

9. Bandura A. Human agency in social cognitive theory. Am Psychol. 1989;44:1175-84.

10. Walker RJ, Gebregziabher M, Martin-Harris B, Egede LE. Understanding the influence of psychological and socioeconomic factors on diabetes self-care using structured equation modeling. Patient Educ Couns. 2015; 98:34-40.

11. McCleary-Jones V. Health literacy and its association with diabetes knowledge, self-efficacy and disease selfmanagement among African Americans with dia-betes mellitus. ABNF J. 2011;22:25-32.

12. Gao J, Wang J, Zheng P, Haardörfer R, Kegler MC, Zhu Y, Fu $H$. Effects of selfcare, self-efficacy, social support on glycemic control in adults with type 2 dia-betes. BioMed Central Family Practice. 2013; 14:66-71.

13. Gastal DA, Pinheiro RT, Vazquez DP. Self-efficacy scale for Brazilians with type 1 diabetes. Sao Paulo Med J. 2007; 125:96-101.

14. Mendez RD, Rodrigues RC, Cornélio ME, Gallani MC, Godin G. [Development of an instrument to meas-ure psychosocial determinants of physical activity behavior among coronary heart disease patients]. Rev Esc Enferm USP. 2010;44:584-96.
15. Hurley, C. A, Harvey RM. The insulin management diabetes self-efficacy scale. In: Strickland OL, Dilorio C, editors. The Measurement of Clinical and Educations Nursing Outcomes. New York, NY: Springer Publishing Commpay; 1990. p. 526-726.

16. Hurley AC, Shea CA. Self-efficacy: strategy for enhancing diabetes self-care. Diabetes Educ. 1992; 18: 14650.

17. Venkataraman K, Kannan AT, Kalra OP, Gambhir JK, Sharma AK, Sundaram KR, et al. Diabetes self-effi-cacy strongly influences actual control of diabetes in patients attending a tertiary hospital in India. J Com-munity Health. 2012;37:653-62.

18. Wu SF, Courtney M, Edwards H, McDowell J, ShortridgeBaggett LM, Chang PJ. Self-efficacy, outcome expectations and self-care behaviour in people with type 2 diabetes in Taiwan. J Clin Nurs. 2007;16(11C):250-7.

19. Chlebowy DO, Myers J, Mendes, AN. Socio-Demo-graphic Variables and Self-Efficacy in Caucasian and African American adults with Type 2 diabetes. South-ern Online Journal of Nursing Research. 2010; 10:174-85.

20. Sharoni S, Khuzaimah A, Wu SFV. Self-efficacy and selfcare behavior of Malaysian patients with type 2 diabetes: a cross sectional survey. Nursing \& health sciences. 2012; 14: 38-45.

21. Trief PM, Teresi JA, Eimicke JP, Shea S, Weinstock RS. Improvement in diabetes self-efficacy and gly-caemic control using telemedicine in a sample of older, ethnically diverse individuals who have diabetes: the IDEATel project. Age Ageing. 2009;38:219-25. 